\title{
APLIKASI INTERACTIVE LEARNING UNTUK BELAJAR BAHASA INGGRIS BUAH-BUAHAN BAGI ANAK-ANAK DENGAN PIRANTI MOBILE SMARTPHONE
}

\author{
Aris Martono ${ }^{1}$ \\ Arsi Yulianjani $^{2}$ \\ Wahyu Hidayat ${ }^{3}$ \\ Dosen STMIK Raharja Tangerang ${ }^{1,2}$, Mahasiswa STMIK Raharja Tangerang ${ }^{3}$ \\ Jl. Jenderal Sudirman No.40 Modernland Cikokol, Tangerang ${ }^{1,2,3}$ \\ e-mail: aris.martono@ raharja.info $^{1},{\text { arsiyulianjani@ } \text { raharja.info }^{2} \text {, wahyuhidayat@ }{ }^{2} \text { raharja.info }}^{3}$
}

\begin{abstract}
ABSTRAK
Tujuan penelitian ini adalah membuat aplikasi interactive learning untuk belajar bahasa Inggris buah-buahan bagi anak-anak dengan piranti mobile smartphone. Kemajuan peralatan teknologi saat ini semakin memudahkan manusia untuk menggunakan dan mengakses semua bentuk informasi, tidak hanya orang dewasa saja tetapi juga anak-anak. Anak-anak ini semakin mahir menggunakan piranti mobile smartphone. Namun kemudahan penggunaan piranti mobile ini membuat kekhawatiran bagi orang tua yang mempunyai anak berumur di bawah 5 tahun. Dikhawatirkan mereka dapat mengakses hal-hal yang belum pantas untuk perkembangan mental. Oleh karena itu penelitian ini dilakukan dengan menggunakan metode survey, analisis dan desain. Penggunaan Adobe Animate CC2018 untuk pembuatan animasi dan Adobe Photoshop CC2018 untuk pembuatan gambar dan karakter. Langkah berikutnya yaitu pembuatan rancangan storyboard, dan rancangan environment serta rancangan menu aplikasi interactive learning bahasa Inggris buah-buahan yang diimplementasikan ke piranti mobile smartphone. Aplikasi ini dapat menumbuhkan minat bagi anak-anak untuk belajar bahasa Inggris buah-buahan dan dapat mengurangi kekhawatiran orang tua.
\end{abstract}

Kata kunci: interactive learning, bahasa Inggris buah-buahan, piranti mobile smartphone

\begin{abstract}
The aim of this research is to create interactive learning applications to learn English fruits for children using Smartphone mobile devices. Current technological equipment advances make it easier for humans to use and access all information forms, not only adults but also children. These children are increasingly adept at using Smartphone mobile devices. However, the ease of use of this mobile device is a concern for parents who have children under 5 years old. It is feared that they can access things that are not appropriate for mental development. Therefore this study was conducted using survey, analysis and design methods. Adobe Animate CC2018 is used for making animations and Adobe Photoshop CC2018 for making images and characters. The next step is the making of storyboard design, and environment design as well as English interactive learning application of fruit menu design that are implemented on Smartphone mobile devices. This application can foster interest for children in learning fruit in English and can reduce parents' concerns.
\end{abstract}

Keyword: Interactive learning, English fruit, Smartphone mobile devices

PENDAHULUAN

Latar Belakang

Perkembangan teknologi saat ini semakin cepat dan semakin maju, namun tak dapat kita hindari. Banyak peralatan teknologi yang berkembang dari hari kehari, seperti komputer, 
telepon, dan lain lain. Kemajuan peralatan teknologi ini ditandai dengan bertambahnya fiturfitur dari peralatan tersebut sehingga memudahkan manusia dalam menggunakan dan mengaksesnya. Peralatan ini diciptakan dan dimanfaatkan dari orang dewasa hingga anakanak.

Namun demikian kemajuan teknologi ini bisa berdampak positif bagi kehidupan manusia atau sebaliknya tergantung yang menggunkannya. Terutama bagi anak-anak karena keingintahuannya yang sangat besar dalam bermain. Anak-anak yang dilahirkan zaman digital ini sudah terbiasa dalam menggunakan peralatan teknologi seperti komputer dan telepon selular. Para orang-tua dengan mudah memberikan kesempatan kepada anak-anak dan membelikan telepone selular yang canggih seperti smartphone atau gadget. Dengan harapan anak-anak dapat belajar bahasa Inggris sambil bermain di dalam smartphone. Namun hal tersebut menimbulkan kekhawatiran bagi orang tua terhadap anak berusia dibawah 5 tahun sehingga harus berhati-hati serta mengawasinya selama menggunakan alat ini.

Untuk mengatasi permasalahan di atas dibutuhkan aplikasi interactive learning bahasa Inggris buah-buahan yang menghibur dan menyenangkan bagi anak-anak dengan piranti smartphone. Selain itu aplikasi ini mendidik anak-anak dan menumbuhkan kinerja otak anak agar tidak bosan dan lebih semangat untuk belajar.

Berdasarkan latar belakang diatas, penelitian ini dilakukan dengan mengembangkan sebuah aplikasi berbasis android yang dapat membantu anak-anak usia dini belajar mengenal nama buah-buahan dalam bahasa Inggris, dan dapat memberikan solusi bagi orang tua yang memiliki anak-anak (di bawah umur 5 tahun), serta mengurangi kekhawatiran mereka terhadap anak-anak mereka dalam menggunakan peralatan teknologi canggih seperti gadget maupun smartphone.

Dengan demikian permasalahan di atas dapat dirumuskan sebagai-berikut:

1. Bagaimana memberikan aplikasi yang baik untuk dimainkan oleh anak-anak?

2. Bagaimana membangun aplikasi edukasi bahasa Inggris buah-buahan yang menarik dan interaktif agar anak-anak dapat bermain dan menyenangkan sehingga menumbuhkan minat belajar?

3. Bagaimana membangun aplikasi interactive learning bahasa Inggris buah-buahan untuk anak-anak yang mudah dimainkan dan menghibur?

Agar penelitian ini terfokus maka diperlukan batasan masalah sehingga permasalahan ini tidak meluas dan sesuai dengan tujuan, yaitu (1) Materi interactive learning difokuskan pada pengenalan buah-buahan; (2) Aplikasi ini difokuskan pada multimedia berupa teks, gambar, suara dan animasi.

Manfaat dari penelitian ini sebagai pendukung proses pembelajaran anak yang bersifat interaktif, menarik dan berkualitas (bermain dan menyenangkan) serta mengenalkan berbagai buah-buahan dalam bahasa Inggris.

\section{Aplikasi Mobile}

Aplikasi merupakan software yang dibuat oleh suatu perusahaan komputer untuk mengerjakan tugas-tugas tertentu, misalnya Ms. Word, dan Ms. Excel. [1]

Subkelas perangkat lunak komputer yang memanfaatkan kemampuan komputer langsung untuk melakukan suatu tugas yang diinginkan pengguna disebut aplikasi. [2]

Aplikasi mobile atau mobile application juga biasa disebut dengan mobile apps, yaitu istilah yang digunakan untuk mendeskripsikan aplikasi internet yang berjalan pada smartphone atau piranti mobile lainnya. Aplikasi mobile biasanya membantu para penggunanya untuk terkoneksi dengan layanan internet yang biasa diakses pada PC atau mempermudah mereka untuk menggunakan aplikasi internet pada piranti yang biasa dibawa. [3] 
Mobile applications is a programs designed to perform a specific functionon mobile computing device (Aplikasi mobile adalah program yang dirancang untuk melakukan functionon spesifik perangkat komputasi mobile). [4]

Perangkat mobile memiliki banyak jenis dalam ukuran, desain dan layout, dengan karakteristik yang berbeda dari sistem desktop, antara lain:

1. Piranti mobile dengan ukurang kecil dimana untuk kenyamanan konsumen dan mobilitasnya.

2. Piranti mobile dengan memori yang kecil dimana primary (RAM) dan secondary memory terbatas.

3. Piranti mobile dengan daya proses terbatas.

4. Piranti mobile dengan daya yang rendah.

5. Piranti mobile yang kuat dan dapat diandalkan dimana mampu menghadapi benturanbenturan, gerakan dan tetesan-tetesan air.

6. Piranti mobile dengan konektivitas terbatas dimana dengan koneksi wireless.

7. Piranti mobile dengan masa hidup yang pendek.

\section{Konsep Android}

Sistem operasi mobile open source yang mencakup sistem operasi, middleware, dan aplikasi berbasis Linux yang dikembangkan oleh Google yaitu Android.[2]

Android merupakan salah satu dari operating system pada telepon selular(ponsel) yang berbasis pemrograman Java dan XML. Umumnya untuk ponsel yang menggunakan android mempunyai fungsi lebih luas dan lebih komplek.[5]

Android operating system is one of new types of operating system in mobile communication device. This operating system has a Linux base. Android provides an open platform for developers to create their own applications to be used by any varied mobile devices (Sistem operasi Android adalah salah satu jenis sistem operasi di perangkat komunikasi selular yang baru. Operating system ini memiliki basis Linux. Android menyediakan platform terbuka bagi para pengembang untuk menciptakan aplikasi mereka sendiri untuk digunakan oleh setiap piranti mobile yang bervariasi). [6]

\section{Karakteristik Android}

Android memiliki 4 karakteristik sebagai berikut:

1. Android dibangun dengan terbuka(open source) sehinggga sebuah aplikasi dapat memanggil salah satu fungsi inti ponsel seperti membuat panggilan, mengirim pesan teks, menggunakan kamera.

2. Android merupakan aplikasi utama dari telepon dan aplikasi pihak ketiga (third-party application) dimana setiap aplikasi dibangun dan memiliki akses yang sama terhadap kemampuan sebuah telepon selular.

3. Hambatan-hambatan dapat diselesaikan dengan Android untuk membangun aplikasi yang baru dan inovatif.

4. Android menyediakan akses yang luas kepada pengguna untuk menggunakan library untuk membangun aplikasi yang semakin baik. Android memiliki sekumpulan tools untuk membantu para pengembang untuk meningkatkan produktivitas dalam membangun aplikasi.

\section{Arsitektur Android}

Arsitektur android terdapat 4 layer yaitu layer linux kernel, layer libraries dan android runtime, layer appliaction framework, dan layer application(lihat gambar 1 di bawah ini). 


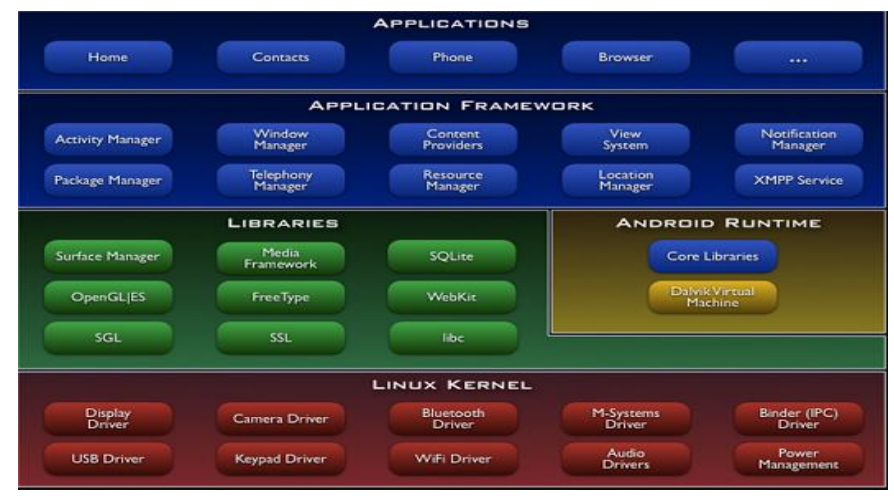

Gambar 1. Arsitektur Android

\section{Konsep Adobe Animate}

Salah satu perangkat lunak computer yang merupakan produk dari Adobe System yang digunakan untuk membuat animasi dan bitmap yang sangat menarik untuk keperluan pembangunan website yang interaktif dan dinamis disebut Adobe Animate. Perusahaan Adobe System merilis Adobe Animate $C C$ sebagai nama baru untuk menggantikan Adobe Flash Professional terlebih pasca banyak platform, browser, dan website tidak lagi menyertakan support untuk animasi Flash yang dikenal berat dan rawan eksploit. Adobe Animate difokuskan pada teknologi animasi menggunakan HTML5 sebagai standard baru untuk animasi interaktif, baik itu untuk keperluan iklan interaktif maupun industri kartun. Lihat gambar 2 tampilan awal adobe animate CC 2018 seperti di bawah ini.

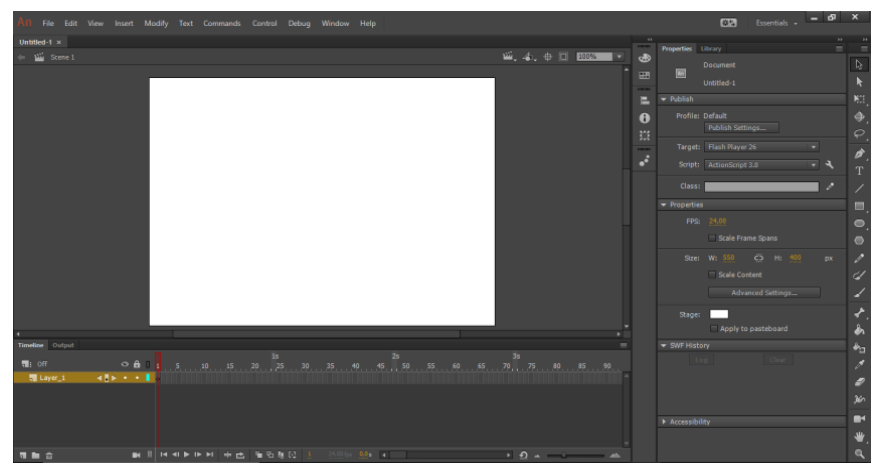

Gambar 2. Tampilan Awal Adobe Animate CC 2018

Aplikasi ini mempunyai fungsi untuk membuat:

1. Animasi

2. Logo

3. Banner

4. Game

5. Karakter

6. Menu interaktif

7. Interaktif form

8. Screen server

\section{Program Aplikasi Penunjang Desain}

Adobe Photoshop adalah perangkat lunak editor citra buatan Adobe Systems yang dikhususkan untuk pengeditan foto/gambar dan pembuatan efek. Perangkat lunak ini banyak digunakan oleh fotografer digital dan perusahaan iklan untuk mengolah gambar/foto. Versi kedelapan aplikasi ini disebut dengan nama Photoshop CS (Creative Suite), versi sembilan 
disebut Adobe Photoshop CS2, versi sepuluh disebut Adobe Photoshop CS3 , versi kesebelas adalah Adobe Photoshop CS4, versi keduabelas adalah Adobe Photoshop CS5, dan versi terbaru adalah Adobe Photoshop CC.

Meskipun pada awalnya Photoshop dirancang untuk menyunting gambar untuk cetakan berbasis-kertas, Photoshop yang ada saat ini juga dapat digunakan untuk memproduksi gambar untuk World Wide Web. Beberapa versi terakhir juga menyertakan aplikasi tambahan, Adobe ImageReady, untuk keperluan tersebut.

Photoshop juga memiliki hubungan erat dengan beberapa perangkat lunak penyunting media, animasi, dan authoring buatan-Adobe lainnya. File format asli Photoshop, .PSD, dapat diekspor ke dan dari Adobe ImageReady. Adobe Illustrator, Adobe Premiere Pro, After Effects dan Adobe Encore DVD untuk membuat DVD profesional, menyediakan penyuntingan gambar non-linear dan layanan special effect seperti background, tekstur, dan lain-lain untuk keperluan televisi, film, dan situs web. Sebagai contoh, Photoshop CS dapat digunakan untuk membuat menu dan tombol (button) DVD.

Photoshop dapat menerima penggunaan beberapa model warna:

1. RGB color model

2. Lab color model

3. CMYK color model

4. Grayscale

5. Bitmap

6. Duotone

Pemahaman elemen dasar dari jendela kerja Photoshop CS5 secara tidak langsung akan meningkatkan produktifitas kerja. Elemen dasar dari jendela kerja Photoshop CS5 diantaranya:

1. Menu Bar atau Baris Menu, berisi barisan perintah berupa menu, seperti menu File, Edit, Image, Layer, Select, Filter, Analysis, 3D, View, Window dan Help.

2. Control Panel atau Option Bar, berisi tombol-tombol pengaturan tambahan, sesuai dengan toolbox yang sedang dipilih.

3. Tools Panel atau Toolbox, berisi tombol-tombol yang mewakili alat atau piranti yang digunakan untuk membuat dan menyunting image atau objek.

4. Area Kerja Image (Active Image Area) atau Document Windows merupakan jendela kerja yang digunakan untuk berkreasi atau menyunting image yang aktif.

5. Collapse to Icon/Expand Panel, pada Photoshop CS5 dapat dengan mudah menutup atau membuka panel sebuah icon.

6. Workshop switcher, digunakan untuk memilih dan mengatur format tampilan jendela kerja (workspace). Untuk memilih dan mengatur workspace dapat juga dilakukan.

Berikut tampilan awal Adobe Photoshop CC 2017 seperti gambar 3 di bawah ini:

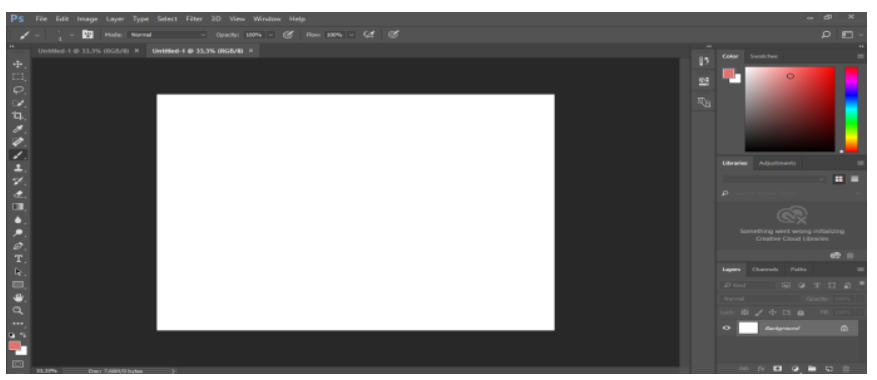

Gambar 3. Tampilan Awal Adobe Photoshop CC 2017

\section{METODE PENILITIAN}

Metode penelitian ini mencakup metode pengumpulan data dan metode pengembangan perangkat lunak. 
Metode pengumpulan data meliputi:

a. Wawancara yaitu cara mengumpulkan data yang dilakukan dengan percakapan yang berbentuk tanya jawab sepihak dan tatap muka pada orang tua berupa daftar pertanyaan, dan merupakan cara memperoleh data yang bersifat langsung.

b. Studi pustaka yaitu dengan mengumpulkan data dan informasi dari literatur, jurnal, paper, peneltian terdahulu serta bacaan-bacaan untuk mendukung pembuatan aplikasi edukasi bahasa Inggris buah-buahan untuk anak-anak.

c. Observasi yaitu metode pengumpulan data dengan mengadakan peninjauan langsung di lokasi agar dapat mengetahui apa saja yang diperlukan untuk membangun aplikasi interactive learning bahasa Inggris buah-buahan untuk anak-anak.

Metode pengembangan perangkat lunak antara-lain:

a. Analisa

Pada tahap analisis ini data hasil survey dianalisis untuk mengetahui kebutuhan apa saja yang dikembangkan dalam aplikasi interactive learning bahasa Inggris buahbuahan dengan smartphone meliputi:

1) Aplikasi yang bersifat interaktif terhadap anak-anak dan dikemas semenarik mungkin.

2) Aplikasi yang menyajikan materi pembelajaran bahasa Inggris buah-buahan.

3) Aplikasi permainan dalam bentuk pertanyaan, soal-soal dan evaluasi serta aturan tertentu untuk menjawabnya.

b. Desain

Tahapan desain ini merupakan tahap membuat rancangan sebuah media pembelajaran model aplikasi dengan mengacu pada hasil analisis kebutuhan dari tahapan analisis sebelumnya. Semua mulai direalisasikan untuk menghasilkan sebuah aplikasi yang dapat digunakan dalam kegiatan pembelajaran. Untuk memudahkan proses pengembangan, maka tahap desain ini menggunakan Adobe Animate CC2018 sebagai pembuatan animasi dan Adobe Photoshop CC2018 sebagai pembuatan gambar dan karakter.

\section{HASIL DAN PEMBAHASAN}

\section{Perancangan Sistem}

Untuk merancang sistem ini diperlukan beberapa tahapan perancangan antara-lain: perancangan storyboard - alur cerita media interaktif dalam bentuk tulisan dan gambar; perancangan background tampilan-latar belakang tampilan gambar; dan perancangan menu - tampilan beberapa fasilitas yang tersedia pada media interaktif tersebut.

\section{Perancangan Storyboard}

Untuk merancangan alur cerita media interaktif dalam bentuk gambar dan tulisan, dirancang dalam storyboard (lihat tabel 1) yang ditampilkan dalam bentuk menu dan beberapa menu pilihan sebagai fasilitas yang tersedia dalam media interaksi ini. 
Tabel 1. Storyboard Menu Utama dan Fasilitas

\begin{tabular}{|c|c|c|c|c|}
\hline \multirow{6}{*}{$\begin{array}{l}\text { VISUAL } \\
\text { Keterangan: } \\
\text { Menampilkan halamanmemu } \\
\text { utama dengan tombol navigasi } \\
\text { yangmemiliki fungs yang } \\
\text { berbeda } \\
\text { Animasi: } \\
\text { tampilan awal mediainteraltif } \\
\text { jika diklik estart> muncul } \\
\text { halaman selanjutrya }\end{array}$} & \multicolumn{3}{|l|}{ SKETSA } & \multirow{7}{*}{\begin{tabular}{|l} 
AUDIO \\
Musik: intro.mp3 \\
Suara: \\
ding.mp 3 (bilamenu dipilih)
\end{tabular}} \\
\hline & \multicolumn{3}{|l|}{ Durasi: } & \\
\hline & \multirow{5}{*}{ Background } & Fruit & & \\
\hline & & Play & & \\
\hline & & Sound & & \\
\hline & & Help & & \\
\hline & & Exit & & \\
\hline \multirow{4}{*}{$\begin{array}{l}\text { Keterangan: } \\
\text { Menampilkan menu utamamedia } \\
\text { interaktif. } \\
\text { Animasi: } \\
\text { Sorotan perubahan warna untuk } \\
\text { menu yang dipilih }\end{array}$} & \multicolumn{3}{|l|}{ Durasi: - } & \multirow{4}{*}{$\begin{array}{l}\text { Musilk: peringatan.mp } 3 \\
\text { Suara: } \\
\text { ding.mp } 3 \text { (bila menu dipilih) }\end{array}$} \\
\hline & \multicolumn{3}{|l|}{ Background } & \\
\hline & \multicolumn{3}{|c|}{ Fruit } & \\
\hline & $\begin{array}{l}\text { Choose } \\
\text { The } \\
\text { Kind of } \\
\text { Fruit }\end{array}$ & $\begin{array}{l}\text { Choose } \\
\text { The } \\
\text { Color } \\
\text { of Fruit }\end{array}$ & $\begin{array}{l}\text { Correct } \\
\text { The } \\
\text { Answer }\end{array}$ & \\
\hline $\begin{array}{l}\text { Keterangan: } \\
\text { Menampilkan halaman quiz } \\
\text { dan next melanjutkan quiz. } \\
\text { Animasi: } \\
\text { Tampilan quiz, jika diklik salah } \\
\text { satu jawaban dan benar } \\
\text { berbunyi 'good' sebaliknya } \\
\text { 'wrong'| }\end{array}$ & \multicolumn{3}{|l|}{ Durasi: - } & $\begin{array}{l}\text { Musilk: peringatan.mp3 } \\
\text { Suara: } \\
\text { ding.mp3 (bila menu dipilih) }\end{array}$ \\
\hline
\end{tabular}

Menu ini merupakan halaman pembuka yang berisi tampilan menu yang dilengkapi beberapa fasilitas yang dapat dipilih penggunanya untuk mencapai tingkatan penguasaan materi. Pada menu ini muncul beberapa fasilitas yang menuju ke level sesuai dengan tingkat kesulitan ataupun fasilitas untuk mengakhiri media interaktif.

\section{Perancangan Environment}

Perancangan environment ini memiliki latar belakang gambar layaknya halaman Padang rumput yang luas serta didampingi animasi yang berbentuk buah di sebelah kanan dan kiri nya untuk membuat kesan aplikasi ini menjadi semakin menarik untuk dapat mempengaruhi keceriaan anak anak yang sedang memainkan aplikasi terserbut. Pada Tampilan Menu nya media pengenalan ini memiliki background yang ceria dan cukup interaktif untuk anak anak yang memainkannya. Hal ini dapat dilihat pada gambar 1 dibawah ini. Untuk memulai permainan aplikasi ini dapat Klik " $P L A Y$ " dan untuk keluar dari aplikasi ini ada Menu EXIT di paling bawah(lihat gambar 4 di bawah ini).

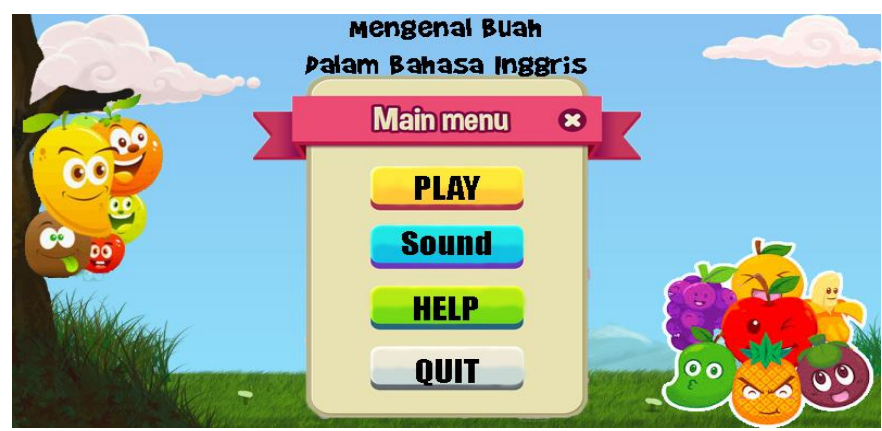

Gambar 4. Tampilan Menu Awal 
Setelah di Klik Tombol "PLAY" disini penulis ingin memberikan 3 bagian tahapan sebagai pilihan untuk memulai nya aplikasi ini, yang terdiri dari "choose the kind of fruits" yaitu menebak jenis buah apakah yang terdapat pada gambar tersebut, kemudian "choose the color of fruits" yaitu menebak Warna apa yang seharusnya pada buah tersebut, dan yang terakhir "correct the answer" yang berarti mencocokan nama buah yang benar, karena kata katanya akan diacak. Tampilan menu pilihan ini dapat dilihat pada gambar 5 di bawah ini.

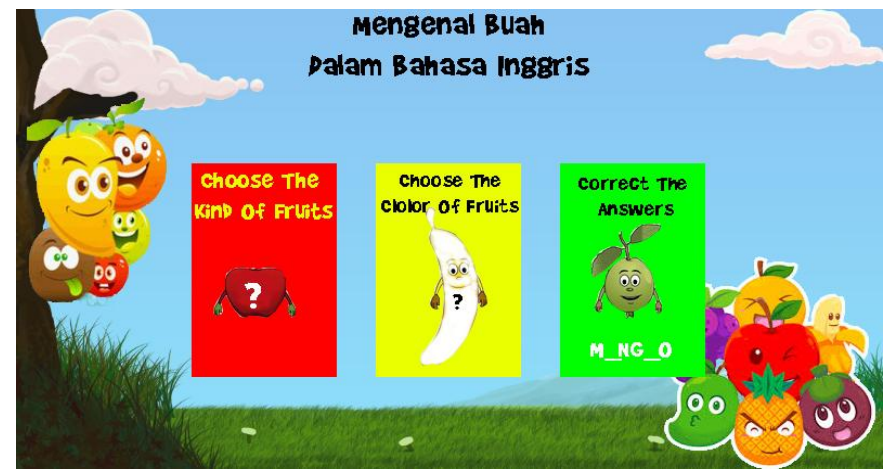

Gambar 5. Tampilan Menu Pilihan

Pada Menu "Choose The Kind Of Fruits" akan menampilkan buah yang memiliki tanda tanya (?) yang dimana pengguna harus menebak jenis buah apakah itu dalam berbahasa inggris tentunya disini akan tersedia beberapa step seterusnya untuk membuat anak anak semakin interaktif dalam belajar mengenal buah Jika interaksi pembelajaran ini jawabannya, system akan menjawab "hooray" disertai dengan animasi buah yang melambai sedangkan jawaban sebaliknya maka system akan merespon "Wrong" disertai animasi yang sedih. Perancangan tampilan gambar 3 di bawah ini menunjukkan background "choose the kind of fruits"'(lihat gambar 6 di bawah ini).

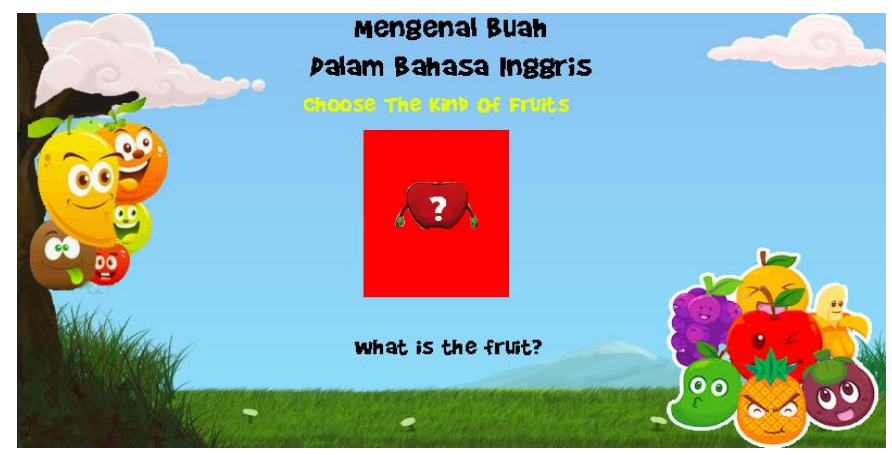

Gambar 6.Tampilan Menu "Choose The Kind Of Fruit"

Pada Menu selanjutnya yaitu "Choose The Color Of Fruits” sama seperti menu yang sebelumnya dimana menu ini akan menampilkan buah yang memiliki tanda tanya (?) yang dimana pengguna harus menebak warna buah apakah itu dalam berbahasa inggris tentunya disini akan tersedia beberapa step seterusnya untuk membuat anak anak semakin interaktif dalam belajar mengenal buah Jika interaksi pembelajaran ini jawabannya, system akan menjawab "hooray" disertai dengan animasi buah yang melambai sedangkan jawaban sebaliknya maka system akan merespon "Wrong" disertai animasi yang sedih. Perancangan tampilan gambar 7 di bawah ini menunjukkan background "choose the color of fruits". 


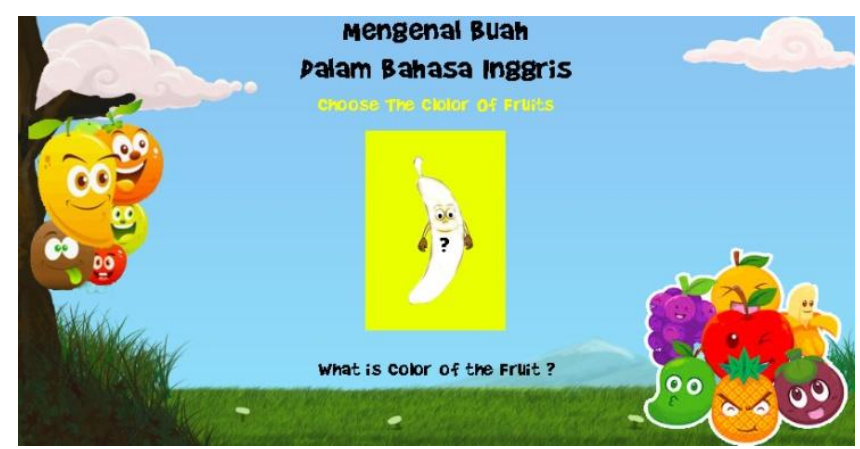

Gambar 7. Tampilan Menu "Choose The Color Of Fruits

\section{KESIMPULAN}

1. Aplikasi yang interactive learning dan bersifat mendidik, mudah dalam penggunaan, dan dapat membantu anak-anak belajar bahasa Inggris tentang nama buah-buahan.

2. Aplikasi yang dilengkapi dengan gambar buah-buahan, berupa animasi untuk mengenalkan buah-buahan dalam bahasa Inggris disertai suara dengan warna buahbuahan yang mencolok.

3. Aplikasi yang interactive learning untuk belajar bahasa Inggris buah-buahan berupa animasi yang berkarakter menghibur bagi anak-anak dan dapat diakses dengan piranti mobile smartphone berbasis android.

\section{DAFTAR PUSTAKA}

1. Asropudin, Pipin., 2013, Kamus Teknologi Informasi Komunikasi, Titian Ilmu, Bandung, ISBN: 978970272927.

2. Safaat, Nazruddin., 2012, Pemograman Aplikasi Mobile Smartphone dan Tablet PC Berbasis Android, Informatika, Bandung.

3. Turban, Efraim., 2012, Electronic Commerce: A Managerial and Social Networks Perspective, Global Edition, Pearson 7th-Global Edition, Paperback, ISBN13: 9780273761341, ISBN10: 027376134X.

4. Seok Kang, 2014, Factors Influencing Intention of Mobile Application Use, International Journal Mobile Communication, Vol.12, No.4, January 2014.

5. Asep Saefullah, Dewi Immaniar dan Reza Amar Juliansah, 2015, Sistem Kontrol Robot Pemindah Barang Menggunakan Aplikasi Android Berbasis Arduino Uno, Jurnal CCIT, Vol. 8, No.2, STMIK Raharja, Tangerang.

6. Kurniawan Teguh Martono dan Oky Dwi Nurhayati, 2014, Implementation of Android Based Mobile Learning Application As A Flexible Learning Media, Internasional Journal of Computer Science, Vol.11, Issues 3 No. 1, May. 